\title{
KULTURMØDER I CYBERSPACE
}

Computermedierede samtaler om livssyn ${ }^{1}$

\author{
Morten Thomsen Højsgaard
}

\section{Indledning}

Møder mellem mennesker med forskellige kulturelle baggrunde har med internettets fremkomst fået et nyt rum at udfolde sig i. Det er et rum, som på én gang er forestillet og faktisk, kunstigt og konkret. Tilstedeværelse i rummet er ikke nødvendigvis knyttet til fysisk nærvær på et bestemt tidspunkt. Snarere er det de forskelligartede kommunikative relationer, der opstår, når mennesker taler til, med og om hinanden på tværs af tid og sted ved hjælp af interaktive computerteknologier, som udgør grundlaget for rummets udformning. Rummet er det såkaldte cyberspace, hvis oprindelige betydning egentlig skal findes inden for science fiktion-litteraturen (Gibson 1984), men som i takt med internettets udbredelse som kommunikationsmiddel i det moderne samfund har fået en bredere og mere praktisk betydnings- og anvendelsesflade som en fællesbetegnelse for "the partly imaginative, partly concrete experience of place that people have when they are engaged in computer-facilitated electronic communications” (Brasher 2001, 29).

Denne artikel handler om nogle af de kulturmøder, der finder sted inden for dette elektroniske felt. De følgende tre spørgsmål udgør fremstillingens ledemotiv: Hvordan manifesterer møder mellem mennesker med forskellige kulturelle baggrunde sig på internettet? Hvilke typer af identifikationsmuligheder og fællesskabsformationer knytter sig til den computermedierede interkulturelle kommunikation? Og hvilke betydninger af begrebet kulturmøde er det egentlig, kulturmøderne i cyberspace indskriver sig i?

Besvarelsen af disse spørgsmål falder i to hoveddele: en afdækning af nogle grundlæggende analytiske spændingsfelter i begreberne kulturmøde og cyberspace og en præsentation af nogle debatfora på internettet, hvor møder mellem forskellige kulturer spiller en vigtig rolle. Den dansksprogede nyhedsgruppe $d k$.livssyn vil i denne forbindelse fungere som det empiriske omdrejningspunkt.

\section{Kulturmøder}

Som analytisk kategori indeholder samlebetegnelsen kulturmøder en række forskellige aspekter. Det skyldes ikke mindst, at begrebets betydning afhænger af, hvilken synsvin-

\footnotetext{
${ }^{1}$ Denne artikel sammenfatter resultaterne af en pilotundersøgelse, som er foretaget i forbindelse med det af Forskningsstyrelsen støttede forskningsprojekt "Studier i religionernes betydning ved identitetsdannelse og fællesskabsformning i kulturmødet i Danmark” (2000-2003) under ledelse af lektor, cand.theol. Hans Raun Iversen, Københavns Universitet.
} 
kel det anskues fra. Hvis kulturmøder f.eks. primært anskues som en relation mellem to parter, kan vi - som den schweiziske historiker Urs Bitterli har foreslået det - gradbøje eller inddele denne relation i mindst fire forskellige hovedtyper: kulturberøring, kulturkontakt, kultursammenstød og akkulturation (Bitterli 1989, 20; Sand 1992, 47). I denne måde at anskue kulturmøder på er det med andre ord intensiteten i relationen, der fokuseres på. En egentlig skala er der ikke tale om, men alligevel kan der spores en udvikling fra den blotte berøring over kontakten til den mere vidtrækkende kulturelle interaktion eller kulturblanding, som akkulturationen indebærer.

Også hos den amerikanske kulturhistoriker Bernhard Lewis er relationer et afgørende karakteristikum ved kulturmøder. Men hvor Bitterli anvender relationernes intensitet eller dybde som indgang til sin rubricering, retter Lewis’ opmærksomhed sig mere mod magtforholdet heri. Kulturmøder fremstår i hans bearbejdning som konfliktforhold, der domineres af enten den ene eller den anden af konfliktens parter. Lewis' kategorier er i overensstemmelse hermed hhv. opdagelse, erobring og fordrivelse (Lewis 1995). Det kan naturligvis diskuteres, hvorvidt sådanne kategoriseringer af det relationelle aspekt $\mathrm{i}$ forbindelse med kulturmøder er dækkende eller tilstrækkeligt rammende. Bitterli fremhæver selv, at “[h]istory, of course, never reveals these basic types in a pure state” (Bitterli 1989, 20). Under alle omstændigheder udgør Bitterlis og Lewis’ værker to forsøg på at nuancere begrebets betydningsspektrum.

En anden måde at nuancere forståelsen af kulturmøder som analytisk begreb på kan opnås ved at betragte de konkrete aktører, der deltager i kulturmødet, som det afgørende for mødets karakter. Når religionshistorikerne Tim Jensen og Alejandro Parellada i en artikel fra 1988 f.eks. taler om de 'store' kulturmøder og de 'mindre' kulturmøder, forekommer det således netop at være aktørniveauet, der udgør forskellen: De store kulturmøder er møder mellem nogle meget brede enheder - civilisationer, verdensreligioner, øst og vest - mens de mindre møder finder sted inden for mere afgrænsede rammer, bestemte traditioner, subkulturer mv. (Jensen \& Parellada 1988, 33; Finnestad 1988, 6 samt Lewis 1995, 7).

Aktørerne i kulturmøderne kan altså billedligt talt være store eller små. Men hvad bestemmer egentlig størrelsen? Geografisk anskuet kan aktørerne i mødet repræsentere lokaliteter med større eller mindre udstrækning: kontinenter, regioner, nationer, landsdele, egne, byer, bydele, gader. Demografisk kan aktørerne repræsentere større eller mindre grupper af befolkningen inden for en lokalitet. Psykologisk kan aktørerne påtage sig eller identificere sig med bestemte roller, når de mødes. Sociologisk, må det tilføjes, kan disse identifikationsprocesser endvidere ses i lyset af parametre som alder, køn, sociale grupper, uddannelse og erhverv. Hermeneutisk, kan vi lægge til, er der stor forskel på, i hvor høj grad aktørerne overhovedet tolker de relationer, de indgår i, som kulturmøder. Principielt er det enkeltpersoner, som taler, handler og oplever i forbindelse med kulturmøder (Eriksen \& Sørheim 2001, 50). Som lingvisterne Ron og Suzanne Wong Scollon har formuleret det: "Cultures do not talk to each other; individuals do" (Scollon 2001, 138). For så vidt kan kulturmøder altså, hvad enten de ud fra en umiddelbar betragtning forekommer store eller små, under ét også beskrives som interpersonelle møder. Set i et bredere analytisk perspektiv forekommer det dog stadig væsentligt at ind- 
drage nogle af de ovennævnte strukturelle vilkår eller kulturelle baggrunde, som møderne mellem de enkelte mennesker finder sted under, med henblik på at afdække disse interpersonelle møders mere specifikke udtryk og særpræg (Brislin 1982, 8; Scollon 2001, 139).

I tillæg til fokuseringen på relationer og aktører kan vi som en tredje mulighed anskue kulturmøder som kommunikative begivenheder. Eller med andre ord: De forskellige måder, kulturmøder formidles på, kan anvendes til at afdække endnu flere brydningsflader i begrebet. Antropologen Edmund Leach, der så en tæt sammenhæng mellem kultur og kommunikation, skelnede i denne forbindelse mellem tre grundlæggende forskellige måder, som den menneskelige kultur kunne komme til udtryk på. For det første: menneskekroppens naturlige biologiske aktiviteter - som f.eks. det at trække vejret. For det andet: tekniske handlinger - såsom det at grave et hul i jorden eller at koge et æg. Og for det tredje: ekspressive handlinger, der udover direkte tale f.eks. også kan indbefatte det at tage en vielsesring på eller det at nikke med hovedet for at signalere noget bestemt (Leach 1976, 9).

I denne opdeling af kulturkommunikationen hos Leach udgør mennesket, forstået som en selvstændig kommunikativ enhed, et centralt punkt. I informationssamfundet medfører mediesituationen imidlertid, at kulturmøder kan udspille sig inden for flere forskellige mediearkitektoniske genrer eller kommunikative rum. Disse spænder lige fra de talte rum, der har samtale som et prototypisk kendetegn, over de skriftlige rum, som f.eks. ytrer sig via breve, og de trykte rum, der bl.a. formidles gennem bøger og aviser, til de analoge elektroniske rum, som bl.a. repræsenteres af radio og tv, samt endelig de digitale elektroniske rum, hvortil specielt kommunikationen på internettet knytter sig (Finnemann 1997, 5). Ved at betragte kulturmøder i forhold til sådanne mere eller mindre adskilte typer af kommunikative kontekster kan vi se endnu et brydningsfelt i begrebet. Det drejer sig om et felt, der strækker sig fra en forståelse af kulturmøder som fysiske hændelser til en opfattelse af kulturmøder som forestillede eller rent medierede forhold.

Endelig spiller ikke blot formen (i form af relations-, aktør- og mediestrukturer) men også indholdet en rolle for brugen af kulturmøder som begrebsramme: Den indholdsbestemmelse eller grundforståelse af fænomenet kultur, som lægges til grund for en undersøgelse af kulturmøder, vil jo uvægerligt få indflydelse på, hvad der kan anses for at høre ind under kategorien. Nogle præciseringer vedrørende opfattelsen af kultur skal derfor medtages her. ${ }^{2}$ I det følgende vil kultur således grundlæggende blive betragtet som det 'tillærte' fremfor det 'medfødte'. Herudover antages det, at kultur ikke skal forstås snævert som finkultur, men bredt som hverdagskultur, f.eks. som de mere eller mindre bevidste vaner og traditioner, livsanskuelser og verdensbilleder, herunder religiøse forestillinger, samt sociale relationer og omgangsformer, der indgår i og kommer til udtryk i menneskers dagligdag. Endelig forudsættes det, at særprægene ved denne hverdagskultur almindeligvis tydeliggøres eller spidsformuleres hos det enkelte menneske,

\footnotetext{
${ }^{2}$ For en mere udførlig diskussion af selve kulturbegrebet henvises bl.a. til Eriksen \& Sørheim 2001, 34-54; Hastrup 1989 samt Scollon 2001, 135-176.
} 
når han eller hun anskuer sig selv i relation til mennesker med en anden kulturel baggrund. Og så er vi jo for så vidt tilbage ved begyndelsen hos Bitterli.

\section{Cyberspace}

Som nævnt optrådte begrebet cyberspace første gang i den amerikanske forfatter William Gibsons science fiktion-roman Neuromancer, der udkom i 1984. Heri beskrives cyberspace bl.a. med udtryk som "bodiless exultation", "consensual hallucination", "unthinkable complexity" og "the non-space of the mind" (Gibson 1984, 12; Hansen 1999, 229; Højsgaard 2001a, 109f). Med afsæt i beskrivelser som disse hos Gibson har der udviklet sig to hovedspor i forståelsen af cyberspace. I det ene spor betragtes cyberspace som en bred samlebetegnelse for virtuelle verdener, forestillede fællesskaber, bevidsthedsmæssige rum eller - endnu mere generelt - nye kulturelle betydningsområder i det postmoderne samfund. I det andet spor knyttes cyberspace i stedet til nogle af de mere specifikke informations- og kommunikationsteknologier, som udgør de redskaber, disse nye kulturelle betydningsområder medieres gennem eller etableres ved hjælp af. Cyberspace kan således både henvise til et symbolsk eller mentalt rum, hvor mennesker kan interagere og kommunikere med hinanden uden fysisk kontakt, og til den konkrete teknologiske infrastruktur, som muliggør den virtuelle interaktion (Brasher 2001, 29; Foster 1997, 24; Hansen, K. 1999, 229; Wilbur 1997, 5).

Men hvad er det så egentlig internettet som teknologi eller infrastruktur kan i forhold til dette at mediere eller etablere virtuelle mødesteder? For det første udgør internettet et ahierarkisk kommunikationssystem, der i lighed med telefonnettet giver brugerne mulighed for at komme i kontakt med hinanden uden en central styring. For det andet er der tale om en mediearkitektur, hvori de enkelte brugere ikke bare er konsumenter af information, som tilfældet almindeligvis er i forbindelse med tv-udsendelser, men faktisk også kan være producenter eller ligefrem distributører af information. Og for det tredje er der tale om en teknologisk organisationsform, der giver mulighed for såvel asynkron som synkron kommunikation i global skala. Dermed mindskes betydningen af samvær i tid og sted som kriterium for menneskelig interaktion (Jensen 1999; Kendall 1999; Poster 1995).

Som kommunikativt rum er cyberspace dog ikke en aldeles entydig størrelse. I en artikel fra 1999 skelner cyber-etnologen Kenneth Hansen f.eks. mellem tre forskellige typer af repræsentation eller visuelle udtryk, som kommunikationen i netværksbaserede medier kan være funderet i. Det drejer sig om henholdsvis endimensional, todimensional og tredimensional kommunikation (se figur 1). 
Figur 1. Taksonomi over netvcerksbaserede medieformer

\begin{tabular}{|c|c|c|}
\hline \multicolumn{3}{|l|}{ Cyberspace } \\
\hline 1D-cyberspace & 2D-cyberspace & 3D-cyberspace \\
\hline E-mail & Internet & Metavers \\
\hline Tekst & Hypertekst & Virtual Reality \\
\hline $\begin{array}{c}\text { Mailinglister } \\
\text { Nyhedsgrupper }\end{array}$ & World Wide Web & $\begin{array}{c}\text { 3D chat } \\
\text { Virtuelle byer }\end{array}$ \\
\hline \multicolumn{3}{|c}{} \\
\hline Tekst $\leftarrow$ 3D Grafik \\
\end{tabular}

Kilde: Hansen, K. 1999, 230.

Tekstbaseret e-mail udgør i denne forbindelse en typisk endimensional udtryksmulighed (1D-cyberspace). Hjemmesiderne på det hypertekstbaserede World Wide Web er derimod typisk todimensionale (2D-cyberspace). Endelig udgør de såkaldte metaverser, som er særlige virtual reality baserede visuelle universer, den tredimensionale udtryksform (3D-cyberspace). Som netværksbaseret medie befinder internettet sig altså ifølge Kenneth Hansen i et kommunikativt spektrum mellem endimensionale tekstuniverser og tredimensionale grafiske landskaber. Sidstnævnte kaldes i Hansens fremstilling for det “egentlige cyberspace” (Hansen, K. 1999, 230). Men det er, sådan som vi bl.a. har set det hos Brenda Brasher, muligt at argumentere for, at det ikke nødvendigvis er den naturtro grafiske gengivelse af et sted, men snarere forestillingen herom, der er konstituerende for cyberspace.

To af de mest centrale tekniske og sociale karakteristika ved fænomenet cyberspace er dog under alle omstændigheder (a) selve netværksstrukturen samt (b) muligheden for interaktion af den ene eller anden karakter inden for denne struktur (Garton et al., 1999, 100; Qvortrup 1998, 201-203). Netop disse karakteristika knytter sig i høj grad til de såkaldte konversationelle services på internettet såsom e-mail, chatrum, debatfora og nyhedsgrupper (Højsgaard 2001b, 102; Jensen 1999, 46-49). Og det er derfor også i nogle medierede samtaler og debatter, der har fundet sted via sådanne services på internettet, den følgende empiriske analyse af kulturmøder i cyberspace tager sit afsæt.

$$
\text { 4. dk.livssyn }
$$

De såkaldte nyhedsgrupper hører til blandt de mest karakteristiske konversationelle services på internettet (Jensen 1999, 48; Smith 1997). En nyhedsgruppe er en form for 
elektronisk læserbrevkasse eller opslagstavle, hvortil alle i princippet kan indsende eller opsætte deres meninger og holdninger eller kommentere andres meninger og holdninger. Kommunikationen i en nyhedsgruppe er i almindelighed baseret på tekst, hvorfor der - for at følge Kenneth Hansens terminologi - almindeligvis er tale om et udtryk for 1D-cyberspace. I nyhedsgrupperne er det brugernes eget ansvar at holde sig til emnet og at være på højde med omgangstonen, for - som regel - er der ingen redaktør, der frasorterer eller modererer de indsendte meddelelser. Nyhedsgrupperne er dog inddelt i nogle overordnede hierarkier, som tilkendegiver, hvad det specifikke sprog- eller emneområde for de enkelte grupper er (Hansen, B. 1999). Desuden knytter der sig i de fleste tilfælde en såkaldt fundats til nyhedsgruppen, som mere præcist beskriver de indholdsmæssige rammer for debatten.

I fundatsen for den dansksprogede nyhedsgruppe $d k$.livssyn, som i det følgende vil være genstand for nærmere analyse, hedder det således:

Emnet for dk.livssyn er subjektiv debat om Livets Store Spørgsmål ... Området lader sig ikke afgrænse med en enkelt elegant definition, men omfatter bl.a.: Filosofi. Etik. Moral. Religion: dogmer, tro og mangel på samme. Metafysik. Verdensbilleder. Formålet med gruppen er at deltagerne kan blive klogere på både deres egen og andres tro/holdning/filosofi ved at forklare den til andre og læse om andres ... Alle bør kunne bruge dk.livssyn til at sammenligne sit livssyn/holdning/religion med andre (Makholm 2000).

Nyhedsgruppen dk.livssyn er altså på det nærmeste designet til at danne ramme om virtuelle kulturmøder. Her kan forskellige personlige livssyn, verdensbilleder og måder at tro på støde sammen, sammenlignes og forklares. Eller sagt på en anden måde: Vi har her at gøre med et forum for interpersonelle møder med et tydeligt markeret og tilsyneladende bevidst valgt kulturelt fortegn. Samtalerne i nyhedsgruppen udspiller sig dog i sagens natur ikke ansigt-til-ansigt, men inden for en ikke-kropslig sfære baseret på computermedieret kommunikation.

Der findes naturligvis andre danske nyhedsgrupper end lige netop $d k$.livssyn, hvor emner som kultur, livsanskuelser og religiøse forhold, spiller en rolle; i nogle af disse er aktivitetsniveauet, som det fremgår af tabel 1, tilmed højere end i dk.livssyn. ${ }^{3}$ Ikke desto mindre forekommer $d k$.livssyn umiddelbart at være den gruppe, der mest eksplicit har dette at mødes på tværs af livsanskuelser og verdensbilleder via internettet som en konstituerende faktor. Flere af de tilgrænsende danske nyhedsgrupper er således enten emnemæssigt afgrænset til én bestemt religion, til en særlig finkulturel forståelse af kultur eller f.eks. til en videnskabelig eller politisk præget meningsudveksling om nogle mindre tværgående emneområder. Derfor er det som udgangspunkt $d k$.livssyn, jeg har valgt at centrere denne analyse omkring. ${ }^{4}$ Som grundlag for analysen har jeg fulgt kommuni-

\footnotetext{
${ }^{3}$ Generelt findes der i dansk sammenhæng mere end 200 forskellige nyhedsgrupper (Tønnesen 2001a), mens antallet på internationalt plan skulle have passeret 100.000 (Smith 1997).

${ }^{4}$ For en mere principiel diskussion vedrørende kriterier for udvælgelse af materiale fra internettet i analytisk øjemed, se Mitra \& Cohen 1999, 192-198.
} 
kationen i gruppen i perioden fra 1. september 2000 til 1. marts 2001. Jeg vil her skitsere nogle typiske træk ved den interaktion, som har udspillet sig i gruppen inden for dette tidsrum.

Tabel 1. Kendetegn for udvalgte danske nyhedsgrupper i år 2000

\begin{tabular}{|l|l|c|c|c|}
\hline Navn & \multicolumn{1}{|c|}{ Emne } & $\begin{array}{c}\text { Brugere } \\
(*)\end{array}$ & $\begin{array}{c}\text { Antal indlæg } \\
\text { i alt }\end{array}$ & Antal pr. dag \\
\hline alt.dk.katolik $\left(^{*}\right)$ & Katolicisme & 13 & 18 & 0 \\
\hline dk.kultur & Finkultur & 27 & 551 & 2 \\
\hline dk.kultur.sprog.klassisk & Filologi & 8 & 218 & 1 \\
\hline dk.livssyn & Livsanskuelse & 53 & 3014 & 8 \\
\hline dk.livssyn.kristendom & Kristendom & 89 & 20705 & 57 \\
\hline dk.livssyn.newage & New Age & 24 & 665 & 2 \\
\hline dk.politik.indvandring & $\begin{array}{l}\text { Samfunds- } \\
\text { forhold }\end{array}$ & 107 & 19065 & 52 \\
\hline dk.videnskab.religion & Forskning & 26 & 1020 & 3 \\
\hline dk.videnskab.teologi & Forskning & 16 & 432 & 1 \\
\hline
\end{tabular}

Kilde: Tønnesen 2001b.

(*) For alt.-hierarkiet har tilgængeligheden af statistiske oplysninger ikke været så god som for dk.-hierarkiet; derfor er opgørelsen over aktiviteter i alt.dk.katolik kun baseret på en periode på $1 / 2$ år, nemlig fra 1. september 2000 til 1. marts 2001.

(**) En bruger defineres her som en e-mailadresse, hvorfra der er blevet indsendt mindst ét indlæg til gruppen.

\section{Kommunikationstypologi}

Overordnet har kommunikationen i dk.livssyn ligesom i de fleste andre nyhedsgrupper været opdelt i en række mere eller mindre afgrænsede delemner eller delforløb, de såkaldte tråde. En tråd kan bestå af alt fra en enkelt henvendelse fra en bruger, som måske ikke engang besvares, til mere omfattende samtaler eller debatter, der kan strække sig over flere måneder og involvere en række forskellige brugere. I alt har der i løbet af perioden fra 1. september 2000 til 1. marts 2001 været 99 af disse adskilte tråde i $d k$.livssyn. I tabel 2 ses en sammenfattende typologisk fremstilling heraf. 
Tabel 2. Typologisk fremstilling af kommunikationen i dk.livssyn i perioden 1. september 2000 til 1. marts 2001

\begin{tabular}{|c|c|c|}
\hline Overordnet karakteristik & Type & Antal tråde (*) \\
\hline \multirow{3}{*}{ Henvendelser } & Markerende & 33 \\
\cline { 2 - 3 } & Opsøgende & 6 \\
\cline { 2 - 3 } & Spontane & 4 \\
\cline { 2 - 3 } & Personlige & 6 \\
\hline \multirow{2}{*}{ Samtaler } & Etiske & 10 \\
\cline { 2 - 3 } & Politiske & 4 \\
\cline { 2 - 3 } & Mediefokuserede & 24 \\
\cline { 2 - 3 } & Livssynsorienterede & 4 \\
\cline { 2 - 3 } & Personlige & \multirow{2}{*}{4} \\
\cline { 2 - 3 } & &
\end{tabular}

Kilde: http://groups.google.com/advanced_group_search.

(*) Som udgangspunkt er de enkelte tråde kun medtaget én gang og det inden for den type, der umiddelbart forekom mest dækkende. Medgives skal det imidlertid, at grænserne mellem de forskellige typer er flydende, og at de angivne tal derfor blot skal betragtes som en vejledende vurdering af, hvor hovedinteresserne i gruppen ligger, snarere end som en eksakt skildring.

Som det fremgår, mener jeg, at der grundlæggende kan skelnes mellem tråde, hvor selve henvendelsen til gruppen er det centrale, og så tråde, hvor det snarere er samtalen eller interaktion $i$ gruppen, som er det kendetegnende. Henvendelserne dækker desuden over kortere forløb i tid og omfang end samtalerne.

Ser vi nu mere specifikt på hovedkategorien ‘henvendelser’, kan den yderligere inddeles i henholdsvis markerende, opsøgende, spontane og personlige henvendelser. De markerende henvendelser er de absolut korteste; til gengæld er der mange af dem. Typisk indeholder de blot en henvisning til en hjemmeside på nettet, som gruppens deltagere så opfordres til at vise opmærksomhed. Blandt de lokaliteter på nettet, der er blevet henvist til i den undersøgte periode, har bl.a. været hjemmesider for eller med religiøse citater, bibelstudier, okkult chat, tankelæsning, tryllekunstnere, tegneserier, islandske heste og net-sex.

I modsætning til sådanne markerende henvendelser forsøger de opsøgende henvendelser ikke at henlede interessen på lokaliteter uden for gruppen, men derimod at få del i 
nogle konkrete informationer fra gruppen: Hvad er 'halloween' egentlig? Hvad er en 'mormon'? Eller hvad er ‘danskhed’? er nogle af spørgsmålene. Og spørgeren har så i de fleste tilfælde fået nogle mere eller mindre subjektive svar fra en eller flere af gruppens øvrige brugere.

Andre henvendelser er mere spontane end egentligt spørgende. Der kan her f.eks. være tale om vittigheder eller såkaldte krydspostninger, dvs. indlæg, der egentlig er tiltænkt et andet forum, men som også sendes til dk.livssyn enten ved en fejl eller for måske alligevel at forsøge at skabe en ekstra interesse for et emne. "Måske er vores jord en anden jord's helvede”, filosoferer en deltager den 22. december 2000. Kun en halv time efter lyder det spontant fra en anden: “Ja, og tænk: Måske betaler de mindre i skat der”. Et tilsvarende indfald offentliggøres den 9. januar 2001: “What is Globalization?”, spørges der, og derefter følger som et indsat svar:

An English princess (Princess Diana) with an Egyptian boyfriend uses a Swedish mobile telephone, crashes in a French tunnel in a German car with a Dutch engine, driven by a Belgian driver, who was high on Scotch, followed closely by Italian Papparazi, on Japanese motorcycles, treated by an American doctor, assisted by Filipino para-medical staff, using Brazilian medicines, dies!

Selv i en sproglig kontekst, der som udgangspunkt er lokalt afgrænset til dansk, er bevidstheden om den globale samtid, som kommunikationen finder sted i, altså latent til stede.

Atter andre henvendelser har en mere personlig karakter. Typisk er der tale om personer, der - i hvert fald sådan som de selv beskriver det - står midt i en krise i livet af enten familiær eller eksistentiel karakter. Og så spørges der åbenhjertigt, om nogle af dk.livssyns læsere måtte sidde inde med et godt råd eller nogen livsvisdom at dele ud af i den forbindelse. Den 19. februar 2001 skriver en kvinde f.eks. om, hvordan hun seks måneder tidligere er blevet forladt af en mand, hun ellers troede var 'manden i hendes liv'. Nu spørger hun så: "Hvordan kan det egentlig være, at det gør så ondt at blive forladt? Og hvorfor kan man ikke bare glemme og komme videre? Hvorfor skal der gå så lang tid med hjertekval?” "Fordi du stadigvæk håber at få ham igen. Håbets dødskamp gør forbandet ondt”, svarer en mandlig deltager. "Håbets dødskamp”, skriver kvinden tilbage den 20. februar - "dér vakte du min eftertanke. Og jeg tænkte bl.a., at så må jeg have et meget stærkt håb, siden den dødskamp varer så længe,” og videre: “Så er den anden side af håbets dødskamp vel håbets vilje til overlevelse. Jeg ved, at jeg har megen kampvilje, når jeg sætter mig mål ... Tusind tak for dit svar på mit indlæg”.

I nogle tilfælde er svarene og den efterfølgende interaktion i gruppen omkring sådanne personlige spørgsmål blevet så omfattende, at det, der som udgangspunkt blot var en henvendelse, dermed har udviklet sig til en egentlig samtale, der involverer større dele af gruppen om f.eks. venskaber, sorg eller tab. Nyhedsgruppen kan altså både prin-

${ }^{5}$ Det skal understreges, at kønsidentiteten i cyberspace ikke kan bestemmes med sikkerhed. I dette tilfælde har jeg blot taget skribenternes egne udsagn herom for pålydende. 
cipielt og reelt karakteriseres som en form for fortløbende, uredigeret læserbrevkasse eller måske ligefrem som et forum for en art kollektiv selvterapi.

Men det er så afgjort ikke blot de personlige spørgsmål, der kan udvikle sig til længere diskussioner. Flere af de mere intense meningsudvekslinger eller samtaler i gruppen drejer sig f.eks. om etiske problemstillinger, herunder specielt spørgsmål vedrørende abort og dødsstraf. Andre tråde er mere politiske i deres tilsnit og handler om emner som Færøernes forhold til Danmark, privatbilisme, demokrati, EU og asylspørgsmål. Ligeledes udgør mediekulturen et selvstændigt debatområde. Pudsigt nok er tendensen her ofte negativ over for f.eks. TV- og IT-kulturen. Ikke uden et gran af selviagttagende, resignerende ironi skriver en bruger f.eks. den 12. februar 2001:

Man kan på sin vis sige at IT-kulturen er kendetegnet ved at folk åbenbart foretrækker ikke at tale med hinanden. Exempelvis maile til hinanden i stedet for at tage telefonen. Internetcaféen må da være det ultimative exempel på dette; et forum hvor folk sidder lige op og ned af hinanden, men i stedet for at snakke med hinanden og måske på den måde møde nye mennesker, så foretrækker man at stirre ret frem og 'møde' personer på andre netcaféer rundt om i verden ... Needless to say foretrækker jeg at tale med folk ansigt-tilansigt, og så kan man jo spørge sig selv om jeg er bedre når jeg sidder her alene foran min computer.

Brugerens iagttagelser skildrer ganske præcist det brydningsfelt mellem forestillede og fysiske fællesskaber, som de computermedierede samtaler mellem forskellige enkeltpersoner indebærer.

De samtaler, der drejer sig om forskellige måder at anskue livet og verden på, hører alt andet lige til blandt de allermest omfangsrige, fortættede eller endog voldsomme diskussionstyper i dk.livssyn. Hvilke idealer skal ligge til grund for undervisningen i folkeskolen? Hvad stiller man op, når man bliver syg? Hvilken mad bør man spise? Hvad skal man mene om staten Israel? Det er spørgsmål af denne slags, der gennemdrøftes. I og for sig er der tale om nogle emner, der har en ganske konkret fysisk eller samfundsmæssig tilknytning. Som en central drivkraft i samtalerne ligger dog det forhold, at deltagerne i nyhedsgruppen qua deres vidt forskellige religiøse og ideologiske udgangspunkter også har vidt forskellige bud på, hvilke svar der har gyldighed i forhold til disse spørgsmål. I en debat om vegetarianisme versus kødspisning legitimeres de fremførte synspunkter f.eks. med referencer til så forskellige autoriteter som Hare Krishnas hjemmeside, vediske tekster, nytestamentlige kilder samt dyreetiske og økonomiske kalkuler. Helt generelt udkrystalliserer der sig således i debatterne i nyhedsgruppen en række brudflader mellem nye religiøse livsanskuelser og mere traditionelle kirkelige synspunkter, mellem såkaldte kirke- og kulturkristne og overordnet mellem religiøse og mere agnostiske tydninger af livet og verden.

Som noget karakteristisk er deltagerne i debatten faktisk meget opmærksomme på, at deres forskellige udgangspunkter fører dem til forskellige svar. Den 29. september 2000 i forbindelse med en debat om globalisering og tro skriver en bruger f.eks. til en anden: "Jeg går ud fra at din sunde fornuft relaterer sig til det videnskabelige verdensbillede. Hvis du var overbevist muslim eller kristen ville resultatet af brugen af ‘den sunde for- 
nuft' se anderledes ud”. Trods selvtydende iagttagelser som denne når deltagerne dog, så vidt jeg kan se, ikke frem til en grundlæggende kulturel konsensus eller en fælles subkulturel identitet. Gudstro og ateisme, myter om livets opståen og evolutionslære, anti-semitisme og zionisme står vedvarende over for hinanden. De individuelle meningstilkendegivelser fortsætter i et uophørligt hverdagskulturelt mindthrill.

\section{Aktivitets- og relationsmønstre}

“Hej, jeg er ny bruger, og vil gerne vide, hvad denne gruppe står for ...”, lød det i et indlæg i dk.livssyn den 14. oktober 2000. "Tja alt mellem himmel og jord :- ${ }^{6}$ Kig eventuelt på fundatsen”, hed det i svaret, som kom samme dag. Under alle omstændigheder fremstår $d k$.livssyn således samlet set som et eksempel på et kommunikativt rum i samtiden, hvor møder mellem nogle meget forskellige måder at opfatte livet og verden på finder sted. Ved at vælge at læse og skrive i nyhedsgruppen $d k$.livssyn går aktørerne således ind i et forum, hvor selve mødet mellem mennesker med forskellige livsanskuelser udgør den erklærede målsætning. De går samtidig ind i en kommunikativ sfære, hvor menneskekroppens biologiske aktiviteter spiller en temmelig ubetydelig rolle, men hvor til gengæld tekniske og ekspressive handlinger via tekst og enkelte tegn er centrale. Magtforholdene i gruppens relationer er således heller ikke knyttet til visuelle socioøkonomiske kendemærker, men til formuleringsevner.

Om intensiteten eller dybden i de relationer, som dette kommunikative rum danner ramme om, er det vanskeligt at sige noget endegyldigt. I kategorierne 'henvendelser' og 'samtaler' kan der vel ses en parallel til Bitterlis begreber 'kulturkontakt' og 'kulturberøring’ eller måske endog i nogle tilfælde 'kultursammenstød’. Som en bruger skriver den 18. december 2000 efter at være blevet beskyldt for at være 'en lallende idiot' af en anden bruger, så har debatten i dk.livssyn ind imellem karakter af 'verbal vold’.

Tabel 3. Aktiviteter i nyhedsgrupper for de ti mest aktive deltagere i dk.livssyn i perioden 1. september 2000 til 1. marts 2001

\begin{tabular}{|c|c|c|}
\hline ID $\left(^{*}\right)$ & $\begin{array}{c}\text { Antal indlæg } \mathbf{i} \\
\text { dk.livssyn }\end{array}$ & $\begin{array}{l}\text { Antal indlæg i nyheds- } \\
\text { grupper i alt }(* * *)\end{array}$ \\
\hline A & 82 & 175 \\
\hline B & 66 & 78 \\
\hline C & 58 & 733 \\
\hline D & 40 & 780 \\
\hline
\end{tabular}

\footnotetext{
${ }^{6}$ En måde at udtrykke ironi og andre følelser på i 1D-cyberspace består i, som det gør sig gældende for skribenten her, at anvende en såkaldt smiley, dvs. en sammensætning af grammatiske tegn, der kan afkodes som et ansigtsudtryk (se evt. Sinclair 1994).
} 


\begin{tabular}{|c|c|c|}
\hline ID $(*)$ & $\begin{array}{c}\text { Antal indlæg } \mathbf{i} \\
\text { dk.livssyn }\end{array}$ & $\begin{array}{l}\text { Antal indlæg i nyheds- } \\
\text { grupper i alt }(* * *)\end{array}$ \\
\hline $\mathrm{E}(* *)$ & 33 & $?$ \\
\hline $\mathrm{F}(* *)$ & 26 & $?$ \\
\hline $\mathrm{G}$ & 26 & 525 \\
\hline $\mathrm{H}$ & 24 & 555 \\
\hline $\mathrm{I}$ & 23 & 276 \\
\hline $\mathrm{J}$ & 19 & 304 \\
\hline
\end{tabular}

Kilde: http://groups.google.com/advanced_group_search.

$\left(^{*}\right)$ Alle personnavne er fjernet for at sikre deltagerne i dk.livssyn anonymitet.

(**) Af tekniske grunde har det desværre ikke været muligt at måle den generelle aktivitet for to af deltagerne.

$\left.{ }^{* * *}\right)$ Som eksempler på nyhedsgrupper, nogle af de ti mest aktive deltagere i dk.livssyn deltager i udover dk.livssyn, kan nævnes alt.3d.studio, alt.mythology, alt.pets.guinea-pigs, alt.religion.asatru, alt.religion.vaisnava, dk.edb.system.unix, dk.kultur.sprog, dk.livssyn.kristendom, dk.livssyn.newage, dk.medier.tv, dk.politik.indvandring, dk.snak.mudderkastning, dk.snak.seksualitet, dk.videnskab.historie, dk.videnskab.sundhed, dk.videnskab.teologi samt w.bbs.soc.kaohsiung.

Tidligere undersøgelser af identitets- og fællesskabsformationer i nyhedsgrupper har peget på, at det særligt er hos de mest aktive deltagere, de såkaldt hyperaktive, at en egentlig gruppeidentifikation eller et fællesskab, der kan sidestilles med konventionelle fællesskaber uden for cyberspace, opstår (Garton et al. 1999; Gotved 1999; Højsgaard 2001b). Hvis vi nu imidlertid sammenligner det aktivitetsniveau, som de ti mest aktive deltagere i $d k$.livssyn har i denne nyhedsgruppe, med deres aktivitetsniveau i nyhedsgrupper på internettet i det hele taget, ja, så forekommer det i grunden ikke rimeligt at argumentere for, at $d k$.livssyn skulle udgøre et selvstændigt community - i hvert fald ikke ud fra en kvantitativ betragtning. Det viser sig nemlig, at de fleste af disse mest aktive deltagere faktisk skriver mere end ti gange så mange indlæg til andre nyhedsgrupper end til dk.livssyn, og den eneste bruger, der næsten kun har ytret sig i $d k$.livssyn (B), holdt faktisk op med at skrive i gruppen omkring midten af januar 2001 (se tabel 3).

For hver enkelt deltager i $d k$.livssyn tegner der sig således et individuelt aktivitetseller relationsmønster, der udover deltagelse i nyhedsgrupperne også indbefatter kommunikation via e-mail, konsultation af forskellige hjemmesider på World Wide Web samt en række andre off-line aktiviteter, eftersom ingen udelukkende lever i cyberspace (Kendall 1999, 70). En person, der i en nyhedsgruppe identificerer sig i forhold til dikotomien religiøs/ikke-religiøs, kan således i en anden gruppe indplacere sig i forhold til 
sit grundsyn på konkurrerende styresystemer som Unix og Windows og i en tredje gruppe med stor passion foretrække et kæledyr frem for et andet. ${ }^{7}$

To tredjedele af Danmarks befolkning har ifølge Danmarks Statistik (2000) adgang til internettet. Af disse deltog blot 53 i løbet af hele år 2000 aktivt som skribenter i dk.livssyn (jf. tabel 1). Flere kan naturligvis have været passive læsere eller lurkers, som det hedder i jargonen. Kulturmøderne må i den del af cyberspace, som kan benævnes dk.livssyn, dog samlet set betragtes som et lille relationsområde, et funktionelt uddifferentieret mini-system, en sociokulturel niche. Det er ikke umiddelbart de såkaldte store kulturmøder, men snarere de mindre af slagsen, der ytrer sig i dette virtuelle forum.

\section{Konklusion}

Det mest åbenlyse karakteristikum ved de kulturmøder i cyberspace, som har været genstand for såvel teoretisk som empirisk analyse i det foregående, er, at de er medierede, altså at de ikke udspiller sig som møder ansigt-til-ansigt, men i stedet finder sted ved hjælp af digitale overførsler af mere eller mindre symbolske meddelelser på internettet. Det rum, som kulturmøderne i cyberspace finder sted i, er således som fysisk enhed nærmest ikke-eksisterende; det etableres først som en forestilling eller et kommunikativt rum i takt med eller som følge af, at den digitalt formidlede interaktion mellem aktørerne finder sted.

Kulturmøder i cyberspace er således også af natur dynamiske størrelser. De eksisterer i kraft af et underfundigt samspil mellem tekniske og sociale interaktionsprocesser. Og de forsvinder som kommunikative organisationer, når disse processer ophører.

I sagens natur har kulturmøder i cyberspace derfor også en udpræget individuel karakter. På internettet er det jo den enkelte bruger, aktør eller surfer, der på en meget direkte måde enten tilvælger eller fravælger interaktionsmuligheder, relationsmønstre, interesseområder, debatforløb og samtalepartnere. For så vidt udgør en nyhedsgruppe som dk.livssyn, hvis erklærede hensigt det er at danne ramme om møder mellem mennesker med forskellige selvforståelser og verdensopfattelser, egentlig lidt af en selvmodsigelse. Selvet i cyberspace lader sig, som vi har set, ikke fastholde i én ramme, ét forum eller ét mødested. Det indgår derimod i en række forskellige individuelt tilrettelagte forbindelser på kryds og tværs af ellers tiltænkte mødepladser, organisationsformer og grupperinger. Den typiske aktør i de virtuelle kulturmøder er således det selvforvaltende individ. Og tre typiske kendetegn ved det virtuelle kulturlandskab er i overensstemmelse hermed heterogenitet, differentiering og proces-orientering.

I $d k$.livssyn er der med andre ord ikke tale om et afgrænset eller ensartet tredje kulturmønster, men snarere om et sammensurium af ' 117 ’ forskellige kulturelle identifikations- og relationsmuligheder. Der er nok tale om et forum for fluktuerende kulturberøringer og religiøse identifikationsmuligheder, men ikke om en såkaldt melting pot, der

\footnotetext{
${ }^{7}$ Teknisk set er det ikke muligt at afgøre, om det i alle disse situationer er den samme person, der har skrevet indlæggene; blot kan det konstateres, at indlæggene alle er afsendt fra den samme e-mailadresse.
} 
på en mere synlig måde kan lede til dannelsen af en ny samlet gruppebevidsthed. Snarere end at fremme den indbyrdes forståelse ser samtalerne i dk.livssyn inden for den undersøgte periode således ud til først og fremmest at understøtte og indgå som led i selvforståelsen hos de forskellige deltagere i gruppen.

Generelt skal den nye digitale informations- og kommunikationsteknologi måske derfor også fraskrives en del af sin ellers ofte tildelte status som en kulturel nyskabelse. Eller sagt på en anden måde: I stedet for at anskue en nyhedsgruppe som dk.livssyn som et eksempel på en ny eller særlig form for kulturelt udtryk, kan vi altså også vælge blot at betragte kommunikationen i gruppen som et spejlbillede af det dagens samfund, som internettet jo konkret befinder sig i, og af de mennesker, der også her indgår i komplekse kulturelle og religiøse forbindelser. Som Lars Qvortrup har formuleret det: “Jamen informationsteknologi er ikke årsag til informationssamfundet. Uden begreber som uddifferentiering og hyperkompleksitet kan man overhovedet ikke give en fornuftig begrundelse for informationsteknologi” $(1998,193)$.

Den kulturelle interaktion på internettet fremstår på denne baggrund ikke som et unikum, men blot som endnu et kildemateriale, der kan medvirke til f.eks. at kaste lys over, hvorledes interpersonelle møder kan udspille sig, hvordan hverdagsprægede relationer kan etableres, eller på hvilke måder almindelige mennesker ser ud til på vidt forskellig vis at kunne konstruere personlige forklaringer eller sammensætte deres egne måder at orientere sig på i dagens informations- og netværkssamfund.

\section{Litteratur}

BITTERLI, URS

1989 Cultures in Conflict. Encounters Between European and Non-European Cultures, 14921800, Cambridge.

BRASHER, BRENDA

2001 Gimme That Online Religion, San Francisco.

BRISLIN, RICHARD W.

1982 Cross-Cultural Encounters. Face-to-Face Interaction, New York.

DANMARKS STATISTIK

2000 PC'ere og adgang til Internet 2000. [Internet]. Tilgængelig via: <http://www.dst.dk/>. ERIKSEN, THOMAS HYLLAND \& TORUNN ARNTSEN SøRHEIM

2001 Kulturforskelle - kulturmøder i praksis, København.

FinNemanN, Niels Ole

1997 Kommunikative rum: Om mediesystemet og andre systemer med variable parametre. [Internet]. Tilgængelig på:

$<$ http://www.hum.au.dk/ ckulturf/pages/publications/nof/kommunikative.htm>.

FINNESTAD, RAGNHILD B.

1988 “Kulturmøter som studiefelt for religionshistorikeren”, Chaos 10, 5-11.

FOSTER, DEREK 


\section{Kulturmøder i cyberspace}

1997 “Community and Identity in the Electronic Village”, David Porter, ed., Internet Culture, New York, 23-38.

Garton, LAURA, CAROLINE HAYTHORNTHWAITE \& BARRY WELLMAN

1999 “Studying On-Line Social Networks”, Steve Jones, ed., Doing Internet Research. Critical Issues and Methods for Examining the Net, Thousand Oaks, 75-105.

GiBSON, WiLLIAM

1984 Neuromancer, London.

GotVED, STINE

1999 Cybersociologi - det samme på en anden måde, København.

HANSEN, BiRTHE

1999 DK-OSS. Ofte stillede spørgsmål - med tilhørende svar. [Internet]. Tilgængelig på: $<$ http://www.usenet.dk/info/dk-oss.html>. Sidst ændret 7.8.1999.

HANSEN, KENNETH

1999 “Internettets sociologi: Et spørgsmål om virtuel kultur”, Jens F. Jensen, ed., Internet, World Wide Web, Netvcerks-kommunikation. Om netmedier, netkulturer, beboede 3D virtuelle verdener og meget mere, Aalborg, 229-61.

HASTRUP, KIRSTEN

1989 “Kultur som analytisk begreb”, Kirsten Hastrup \& Kirsten Ramløv, eds., Kulturanalyse. Fortolkningens forløb i antropologien, Viborg, 11-21.

HøJsGaARD, MORTEN THOMSEN

2001a “The Cyberpunk’s Prayer: På tværs af traditionshistorie og samtidshistorie”, Lene Buck, Morten Thomsen Højsgaard \& Lakshmi Sigurdsson, eds., Kristendomshistorie på tvæers, København, 105-125.

2001b “Virtuelle lokaliteter: Dansk kristendom på Internettet”, Chaos 35, 99-115.

JENSEN, JENS F.

1999 "Roadmap til informationsmotorvejen: Medietypologier for informationstrafikmønstre på Internet”, Jens F. Jensen, ed., Internet, World Wide Web, Netvcrks-kommunikation. Om netmedier, netkulturer, beboede 3D virtuelle verdener og meget mere, Aalborg, 25-68.

JENSEN, TIM \& ALEJANDRO PARELLADA

1988 “Teologien i dansehuset: Religionsforskeren som aktør i det afro-brasilianske kulturmøde”, Chaos 10, 24-41.

KENDALL, LORI

1999 “Recontextualizing 'Cyberspace': Methodolocical Considerations for On-line Research”, Steve Jones, ed., Doing Internet Research. Critical Issues and Methods for Examining the Net, Thousand Oaks, 57-74.

LEACH, EDMUND

1976 Culture \& Communication. The Logic by which Symbols are Connected, Cambridge.

LEWIS, BERNHARD

1995 Cultures in Conflict. Christians, Muslims, and Jews in the Age of Discovery, New York.

MAKHOLM, HENNING

2000 Danske nyhedsgrupper: dk.livssyn. [Internet]. Tilgængelig på:

$<$ http://www.usenet.dk/grupper.pl?get=dk.livssyn>. Sidst ændret 2.2.2001. 
Mitra, ANANDA \& ELISIA COHEN

1999 “Analyzing the Web: Directions and Challenges”, Steve Jones, ed., Doing Internet Research. Critical Issues and Methods for Examining the Net, Thousand Oaks, 179-202.

POSTER, MARK

1995 “Postmodern Virtualities”, Mike Featherstone \& Roger Burrows, eds., Cyberspace/Cyberbodies/Cyberpunk, Thousand Oaks, 79-95.

QVORTRUP, LARS

1998 Det hyperkomplekse samfund. 14 fortællinger om informationssamfundet, København.

SAND, ERIK REENBERG

1992 "Fra kulturmøde til kulturhistorie. Nogle træk af europæernes opfattelser af indianerne fra Columbus til 1700-tallets slutning”, Tove Tybjerg \& Hjørdis Nielsen, eds., Møde mellem to verdener. Amerikas opdagelse fra prcecolumbiansk til nyeste tid, København, 35-49.

SCOLLON, Ron \& SUZANnE WONG SCOLlon

2001 Intercultural Communication, Second Edition, Oxford.

SinClAIR, PAULINE

1994 The Unofficial Smiley Dictionary. [Internet]. Tilgængelig på: $<$ http://paul.merton.ox.ac.uk/ascii/smileys.html>.

SMITH, MARK A.

1997 “Measuring and Mapping the Social Structure of Usenet”. [Internet]. Tilgængelig på: $<$ http://www.sscnet.ucla.edu/soc/csoc/papers/sunbelt97/Sunbelt_Talk.htm>.

TøNNESEN, JENS

2001a Danske nyhedsgrupper. [Internet]. Tilgængelig på: <http://www.usenet.dk/>. Sidst ændret 31.1.2001.

2001b Statistik over dk-hierarkiet. [Internet]. Tilgængelig på: $<$ http://www.usenet.dk/statistik/index.html>. Sidst ændret 9.1.2001.

WILBUR, SHAWN P.

1996 “An Archeology of Cyberspaces. Virtuality, Community, Identity”, David Porter, ed., Internet Culture, New York, 5-22.

\section{Summary}

This article deals with cultural encounters in cyberspace from a theoretical as well as an empirical point of view. It is argued that cultural encounters can be seen as (i) relations of varying intensity, (ii) encounters between individuals situated in diverse structural contexts, (iii) communicative actions that are influenced by the complex media genres of modern society, and (iv) expressions of everyday life. Moreover, it is argued that the notion of cyberspace can be profitably defined as the semi-imaginative experience of place that people have when they take part in conversational communication on the Internet. Based on an analysis of a number of intercultural conversations that have taken place within the newsgroup dk.livssyn from 1 September 2000 to 1 March 2001, the article concludes that, in general, the cultural encounters within this online context seem to be fluctuating, dynamic, and highly individually constructed. 
Morten Thomsen Højsgaard Ph.d.-studerende, cand.mag. Institut for Religionshistorie Københavns Universitet 